\title{
The Effect of Gibberellin on Somatic Embryo Growth and Maturation and Plantlet Regeneration of Tangerine (Citrus reticulata Blanco.) var. Batu 55
}

\author{
Elok Rifqi Firdiana ${ }^{1}$, Serafinah Indriyani ${ }^{2}$,Wahyu Widoretno ${ }^{2 *}$ \\ ${ }^{1}$ Master Program of Biology, Faculty of Mathematics and Natural Sciences, University of Brawijaya, Malang, Indonesia \\ ${ }^{2}$ Department of Biology, Faculty of Mathematics and Natural Sciences, University of Brawijaya, Malang, Indonesia
}

\begin{abstract}
The effect of gibberellin at multiplication stage on somatic embryo growth and maturation and plantlet regeneration of tangerine (Citrus reticulata Blanco.) var. Batu 55 was assessed. Somatic embryo at globular phase was cultured on MT media $+30 \mathrm{gL}^{-1}$ sucrose and various concentrations of gibberellin $(0,2,4,6$, and $8 \mathrm{ppm})$. The somatic embryo was maturated on MT media $+500 \mathrm{ppm}$ malt extract $+73 \mathrm{mM}$ sorbitol $+73 \mathrm{mM}$ galactose. Cotyledonary somatic embryo was regenerated into plantlet on MT media $+500 \mathrm{ppm}$ malt extract $+30 \mathrm{gL}^{-1}$ sucrose $+2 \mathrm{ppm} \mathrm{GA}$. The results showed that the addition of gibberellin in somatic embryo multiplication stage increased somatic embryo growth and maturation and plantlet regeneration of tangerine. Optimum concentration of gibberellin needed for somatic embryo growth was $4 \mathrm{ppm}$ which yielded two-fold fresh weight compared to control. The percentage of maturation was very low below $5 \%$. The addition of gibberellin in media at embryo multiplication stage slightly increased the percentage of maturation about $1-2 \%$. Thirty percent of cotyledonary embryo was able to regenerate into plantlet. The addition of gibberellin in media at embryo multiplication stage increased the regeneration percentage, even the addition of $8 \mathrm{ppm}$ gibberelline yielded regeneration percentage up to $70 \%$.
\end{abstract}

Keywords: gibberellin, growth, maturation, plantlet regeneration, somatic embryo

\section{INTRODUCTION}

Tangerine var. Batu 55 is one of local citrus varieties that has several special characters such as sweet, easy to peel, and almost seedless. These characters cause the high demand of tangerine, but it is still unfulfilled by national production. The fulfillment of national tangerine need was constrained by the procurement of large amount of good seeds. The effort to handle this problem was already conducted by using tissue culture technique through somatic embryogenesis method. Unfortunately, the plants regenerated from somatic embryo had long juvenile period [1]. Along with this reason, the endeavor to multiply seeds with shorter juvenile period was important.

Several tissue culture-derived plants with shorter juvenile period such as Phoenix dactylifera [2,3] and Cymbidium niveomarginatum Mak [4] were successfully regenerated by means of media modification. The media modification used was the addition of gibberelline. Gibberelline is a plant growth regulator that plays role in flowering. According to

\footnotetext{
* Correspondence author:

Wahyu Widoretno

Email : wahyu_widoretno@yahoo.com

Address : Department of Biology, University of Brawijaya, Jl. Veteran Malang, 65145
}

Blazques [5], gibberelin is able to shorten the juvenile period because it activates LEAVY promoter, gene that responsible for flowering.

In somatic embryogenesis, giberelin was evidenced to trigger embryo maturation of Medicago sativa [6] and plantlet regeneration of Vitis vinifera [7], but it inhibited somatic embryo maturation of Daucus carota [8]. Therefore, it was important to assess the effect of gibberellin on somatic embryo growth and maturation and plantlet regeneration of Tangerine var. Batu 55.

\section{MATERIALS AND METHODS}

Induction and multiplication of somatic embryo

Somatic embryo was obtained from previous study [9]. Embryogenic calli were multiplied through subculture every six weeks and cultured on MT media $+30 \mathrm{gL}^{-1}$ sucrose. After three times subcultures, the somatic embryo was used for gibberellin treatment.

\section{Gibberellin treatment}

Somatic embryo at globular phase was cultured on MT media $+30 \mathrm{gL}^{-1}$ sucrose + various gibberellin concentrations $(0,2,4,6$, and $8 \mathrm{ppm})$. Every treatment was repeated five times (5 bottles) and every bottle was filled with one clump of embryo. The embryo was maintained for two months. The morphology and the fresh weight were observed. 


\section{Somatic embryo maturation and plantlet rege- neration}

Somatic embryo maturation was carried out on MT media +500 ppm malt extracts $+73 \mathrm{mM}$ sorbitol $+73 \mathrm{mM}$ galactose. Maturation culture was maintained in room temperature for three months. Percentage of maturation was calculated by using this formula:

$$
\% \text { maturation }=\frac{\text { the amount of cotyledone embryo }}{\text { the amount of total embryo }} \times 100 \%
$$

Cotyledone embryo as the result of maturation was regenerated into plantlet by culturing it on $\mathrm{MT}$ media $+30 \mathrm{gL}^{-1}$ sucrose $+500 \mathrm{ppm}$ malt extract $+2 \mathrm{ppm} \mathrm{GA}$. Percentage of regeneration was determined by using this formula:

$\%$ regeneration $=\frac{\text { the amount of plantlet }}{\text { the amount of cotyledone embryo }} \times 100 \%$

\section{Data analysis}

Data were analyzed using ANOVA. If there were any siginificant differences, analysis was continued using Duncan test ( $\alpha$ : 0.05).

\section{RESULT AND DISCUSSION \\ Effect of gibberellin on the growth of somatic embryo}

Somatic embryo of Tangerine var. Batu 55 was friable and yellowish white. The growth of somatic embryo increased with the addition of gibberellin. The clumps of somatic embryo cultured in gibberellin media were apparently bigger compared to control (Fig. 1B-E). The addition of gibberellin in media increased the fresh weight of somatic embryos. The fresh weight of somatic embryo cultured in gibberellin media was significantly higher compared to control (Fig. 2). Optimum gibberellin concentration for somatic embryo growth was $4 \mathrm{ppm}$, giving the highest fresh weight $(0.71 \mathrm{~g})$, almost two-fold compared to control $(0.37 \mathrm{~g})$.

The proliferation of somatic embryo is related to the maintenance of embryogenic competence, in this term assumed as the growth of somatic embryo. Gibberellin caused various effects on the growth of somatic embryo in different species. In Medicago sativa, gibberellin enhanced somatic embryo growth [6], while in Centaurium erythraea it caused contrary effect [10]. The different result showed that beside plant regulator, the genotype was also a determining factor for somatic embryogenesis.
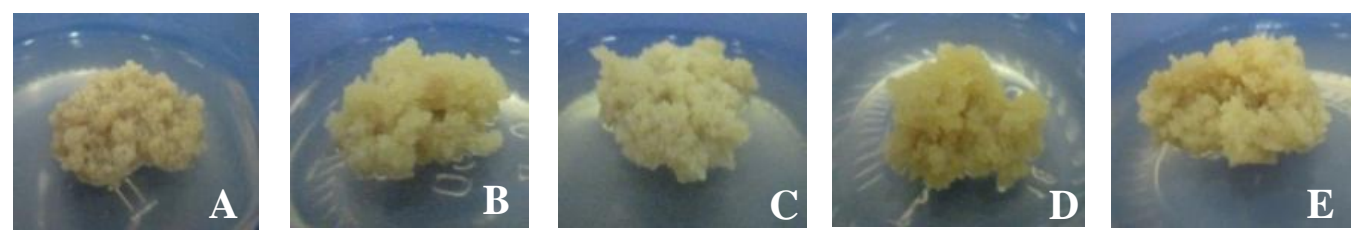

Figure 1. The growth of somatic embryo cultured in gibberellin media A. Gibberellin 0 ppm (control); B. Gibberellin 2 ppm; C. Gibberellin 4 ppm; D. Gibberellin 6 ppm; E. Gibberellin 8 ppm.

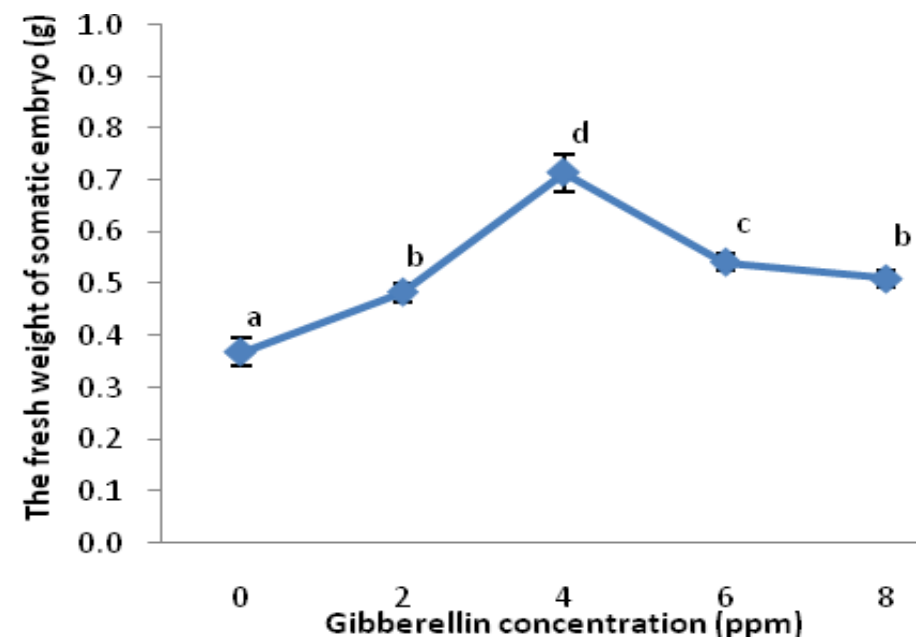

Figure 2. The effect of gibberellin on the fresh weight of somatic embryo. The same letter did not show significant difference using Duncan's test $(\alpha ; 0.05)$. 


\section{Effect of gibberellin on somatic embryo matura- tion and plantlet regeneration}

The maturation of somatic embryo indicated the cessation of somatic division and occurance of differentiation. Somatic embryo maturation in tangerine was observed one month after the globular somatic embryo was transferred into maturation media. The markings of maturation were the change of shape and color of embryo that previously yellowish white globular embryo (Fig. 3A) into the next phase that greenish in color (Fig. 3B). The embryo maturation consisted of several phases: globular, heart, and cotyledone. Unfortunately, the torpedo phase was rarely seen. The embryo that already entered cotyledone phase was considered mature (Fig. 3C). The mature embryo was transferred into regeneration media to yield plantlet. The obtained plantlets were about $1.5-2 \mathrm{~cm}$ with primary roots and leaves (Fig. 3D).

The maturation of somatic embryo was very low. The maturation percentage was only below $5 \%$, but the addition of gibberellin in media at embryo multiplication stage slightly increased the maturation. Somatic embryo cultured on media that contained gibberellin up to $4 \mathrm{ppm}$ could yield higher maturation percentage. However, the maturation was inhibited in embryo that multiplied on media containing higher gibberellin concentration (Fig. 4).

The addition of gibberellin in media at embryo multiplication stage not only increased somatic embryo maturation but also the plantlet regeneration. The significant increment of percentage regeneration was obtained from somatic embryo that multiplied in media containing gibberellin of $8 \mathrm{ppm}$. It contibuted to the highest regeneration percentage $(70 \%)$, almost twice as control (36\%) (Fig. 4).

Somatic embryo maturation was still a crucial problem of Tangerine var. Batu 55 somatic embryogenesis. The low conversion rate in many species from globular somatic embryo to the next phases might be caused by the low quality of somatic embryo or the somatic embryo had developed tolerance toward desiccation [11]. Whereas, maturation should not only be synthetical phase and accumulation of food reserve, but also the end of desiccation tolerance. Thus, desiccation played important role in transition period between embryogenic phase and germinative phase.

The effect of gibberellin that increase the growth and maturation of somatic embryo was also observed in Tylophora indica (Burm. f.) Merrill somatic embryo [12]. Different result was obtained in Arabidopsis somatic embryo in which gibberellin inhibited maturation of somatic embryo [13].

The improvement of regeneration of plantlet by gibberellin was related to the activation of $\alpha$ amylase genes. This activation caused activity acceleration of the $\alpha$-amylase activity and the enhancement of starch hydrolysis into sugar occured [14]. Hence, the plantlet development by means the elongation of the embryos axis took place [15]. The regeneration plantlet was also affected by the quality of the morphology cotyledonary embryo. Cotyledonary embryo morphology was important for plantlet regeneration [16]. The regeneration could occur only if the embryo had good polarization: a root axis and well-developed shoot (a hypocotyl and two cotyledons).

Exogenous plant growth regulator could be viewed as supplement for endogenous hormone, or conversely, it could be destructive for hormonal balance [8]. According to the result of this study, it could be noted that the gibberellin concentration used had already proper to support the balance of endogenous hormonal of Tangerine somatic embryo.
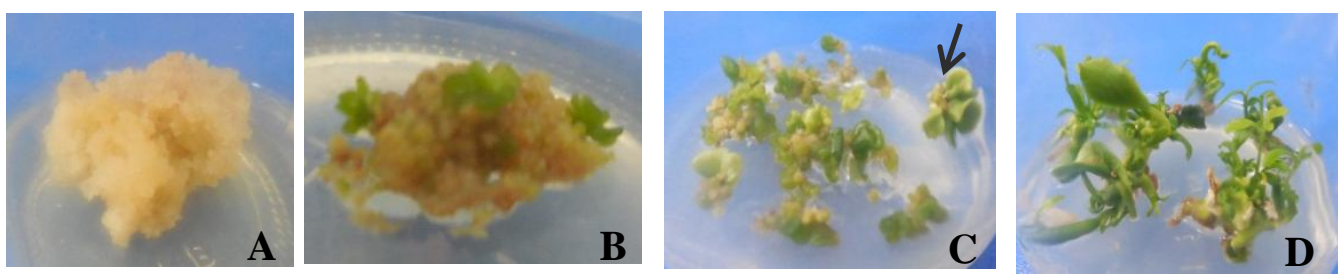

Figure 3. Steps of somatic embryo maturation and plantlet regeneration of Tangerine

A. Clump of globular somatic embryo, B. Somatic embryo showing the markings of maturation, C. Advanced maturation, D. Plantlet. Arrow showed cotyledon phase. 


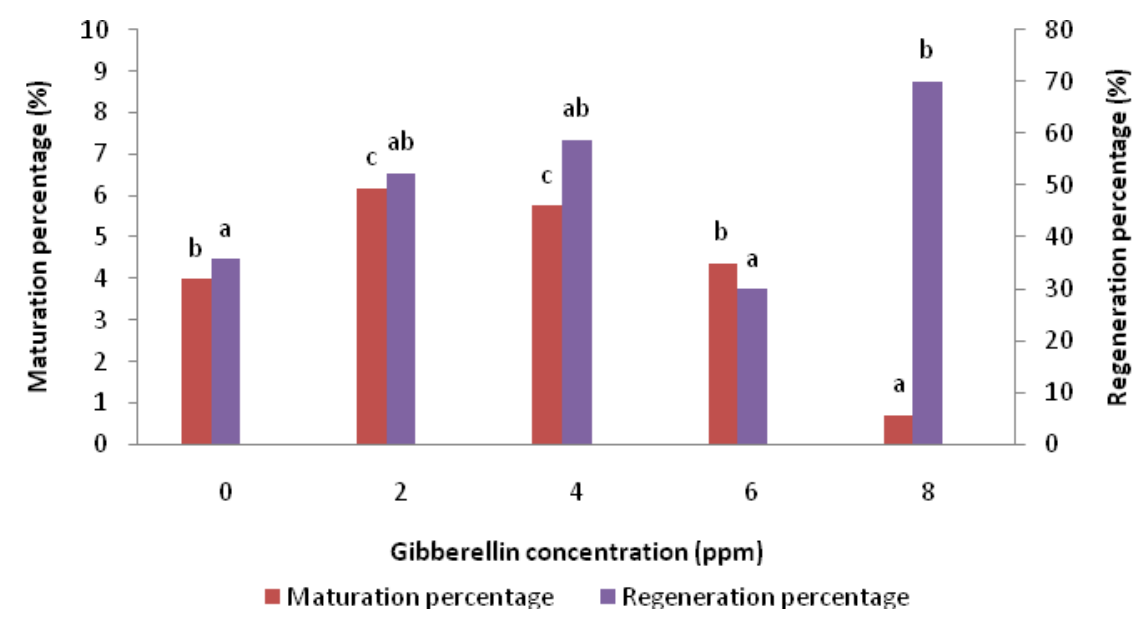

Figure 4. The percentage of somatic embryo maturation and plantlet regeneration of tangerine var. Batu 55 The same letter at the same bar did not show any significant different using Duncan's test ( $\alpha$ : 0.05$)$.

\section{CONCLUSION}

Gibberelin increased somatic embryo growth and maturation and plantlet regeneration of Tangerine var. Batu 55. The highest fresh weight was reached by the addition of $4 \mathrm{ppm}$ gibberellin in culture media, almost twice as control. The percentage of maturation was very low below $5 \%$. The addition of gibberellin in media at embryo multiplication stage slightly increased the percentage of maturation about $1-2 \%$. Thirty percent of cotyledonary embryo was able to regenerate into plantlet. The addition of gibberellin in media at embryo multiplication stage increased the regeneration percentage, even the embryo cultured on media containing 8 ppm of gibberelline yielded the highest regeneration percentage.

\section{REFERENCES}

[1] Jain, S.M., P.K. Gupta, R.J. Newton. 2000. Somatic embryogenesis in woody plants. Kluwer Academic Publishers. Dordrecht.

[2] Al-Khateeb, A.A., H.S. Ghazzawy. 2015. Influence of polyethylene glycol and gibberelline on somatic embryogenesis of date palm (Phoenix dactylifera) cv Sukkary. J. Global Biosc. 4 (6). 2446-2451.

[3] Al-Khayri, J.M., S.M., Jain, D.V. Johnson. 2015. Date palm genetic resources and utilization. Springer. New York.

[4] Kostenyuk, I., B.J. Oh, I.S. So. 1998. Induction of early flowering in Cymbidium niveo-marginatum Mak. Plant Cell Reports. 19. 1-5.

[5] Blázquez, M.A., R. Green, O. Nilsson, M.R. Sussman. 1998. Gibberellins promote flo- wering of Arabidopsis by activating the LEAFY promoter. Plant Cell. 10. 791-800.

[6] Rudus, I., E. Kepczynska, J. Kepczynski. 2002. Regulation of Medicago sativa L. Somatic embryogenesis by gibberellins. Plant Growth Reg. 36. 91-95.

[7] Lopez-perez, A.J., J. Carreno, M. Dabauza. 2006. Somatic embryo germination and plant regeneration of three grapevine cvs: effect of IAA, GA3 and embryo morphology. Vitis. 45 (3). 141-143.

[8] Tokuji, Y., K. Kuriyama. 2003. Involvement of gibberellin and cytokinin in the formation of embryogenic cell clumps in carrot (Daucus carota). J. Plant Physiol. 160. 133141.

[9] Hidayahti, N., W. Widoretno, R. Mastuti. 2013. Pengaruh osmolit terhadap maturasi embrio somatik jeruk (Citrus reticulata Blanco.). El-Hayah. 3 (2). 83-87.

[10] Suboti, A., Jevremovic, M. Trifunovic, M. Petric, S. Miloševic, D. Grubišic. 2009. The influence of gibberellic acid and paclobutrazol on induction of somatic embryogenesis in wild type and hairy root cultures of Centaurium erythraea Gillib. Afr. J. Biotechnol. 8 (14). 3223-3228.

[11] Corredoira, E., A. Ballester, A.M. Vieitez. 2003. Proliferation, maturation, and germination of Castanea sativa Mill. somatic embryos originated from leaf explants. Ann. Bot.-London. 92. 129-136.

[12] Thomas, T.D. 2006. Effect of sugars, gibberellic acid and abscisic acid on somatic embryogenesis in Tylophora indica (Burm. f.) Merrill. Chinese J. Biotechnol. 22. 465-471. 
[13] Zheng, Q., Y. Zheng, S.E. Perry. 2013. AGAMOUS-Like15 promotes somatic embryogenesis in Arabidopsis and soybean in part by the control of ethylene biosynthesis and response. Plant Physiol. 161. 21132127.

[14] Haddadi, P., A. Moieni, Gh. Karimzadeh, M.R. Abdollahi. 2003. Effects of gibberellin, abscisic acid and embryo desiccation on normal plantlet regeneration, secondary embryogenesis and callogenesis in microspore culture of Brassica napus L. cv.PF704. Int. J. Plant Prod. 2(2). 153-162.

[15] Kepczynska, E., S. Zielinska. 2006. Regulation of Medicago sativa L. somatic embryos regeneration by gibberellin $A_{3}$ and abscisic acid in relation to starch content and $\alpha$ amylase activity. Plant Growth Reg. 49. 209217.

[16] Martinelli, L., I. Gribaudo. 2001. Somatic embryogenesis in grapevine. In: RoubelakisAngelakis, K. (Ed.). Molecular Biology and Biotechnology of the Grapevine. Kluwer Academic Publishing. London. 